The Bangladesh Veterinarian (2014) 31(2): 55 - 59

\title{
Peste des Petits Ruminants (PPR) virus antibodies in goats and cattle of the Saint Martin's Island in Bangladesh
}

\author{
MSI Siddiqui, A Ahasan, N Islam, P Kundu, MN Munshi ${ }^{1}$ and EH Chowdhury* \\ Department of Pathology, Faculty of Veterinary Science, Bangladesh Agricultural \\ University, Mymensingh-2202, Bangladesh
}

\begin{abstract}
Peste des petits ruminants (PPR) is a highly contagious acute viral disease of domestic and wild ruminants particularly goats and sheep, which causes severe economic losses. Since 1993 PPR has been endemic in goats in Bangladesh. The present study was a seroprevalence study of PPR antibodies in goats and cattle at St. Martin's Island in Bangladesh from July 2012 to June 2013. There was no previous history of Rinderpest or PPR outbreak, and no Rinderpest vaccination. Blood samples were collected from 192 goats and 132 cattle randomly. All animals were apparently healthy, and were not vaccinated against Rinderpest or PPR. Serum antibody titre (competition percentage; CP value) was determined by a commercially available c-ELISA kit. The overall seroprevalence of PPR in goats was $37.5 \%$. No serum samples from cattle were positive. In view of the high risk of PPR, a control strategy is proposed. (Bangl. vet. 2014. Vol. 31, No. 2, 55 - 59)
\end{abstract}

\section{Introduction}

St. Martin's Island is a small island of 8 sq.km. in the north east of the Bay of Bengal, about $9 \mathrm{~km}$ south of the tip of the Cox's Bazar - Teknaf peninsula, and forming the southernmost part of Bangladesh. Approximately 7000 inhabitants live primarily from fishing. Total animal population is about 1000 of which around 600 are goats, 25 sheep and 375 cattle. Map of Saint Martin's Island is shown in Fig. 1.

PPR is an acute, highly contagious viral disease of sheep and goats and is characterized by fever, anorexia, ulcerative necrotic stomatitis, diarrhoea, purulent ocular and nasal discharges and respiratory distress (Lefevre and Diallo, 1990; Chowdhury et al., 2014), which may be associated with coughing, pneumonia and death. In non-endemic areas mortality and morbidity can reach 90 and 100\%, respectively (Hussain et al., 2003). Concurrent bacterial, viral or parasitic infections may aggravate the condition, and mortality may rise to 100\% (Kitching, 1988). The causative agent of this economically important disease is a Morbillivirus, the Peste des petits ruminant's virus (PPRV), under the family Paramyxoviridae of order Mononegavirales (Murphy et al., 1999). The virus is closely related to Rinderpest virus (RPV), another member of Morbillivirus genus, which causes similar disease in large ruminants (Couacy-Hyman et al., 1995). The virus is serologically related to Measles

\footnotetext{
1Senior Scientific Officer, Bangladesh Livestock Research Institute, Savar, Dhaha

*Corresponding author:- E-mail: emdad001@yahoo.com
} 
(MV) and Canine distemper viruses (CDV) (Gibbs et al., 1979). A varying degree of cross-protection in vivo and serological relationship exists between PPR and RPV (Hamdy et al., 1976; Taylor and Abegunde, 1979). PPR infection in sheep and goats protects in-contact bovines from natural infection, and may interfere in tissue culture Rinderpest virus (TCRPV) vaccination response (Sudharshan et al., 1995). The disease has been reported from many countries of the world including most parts of Africa, Middle East (Lefevre et al., 1991), the Arabian Peninsula (Abu-Elzein et al., 1990), southern Asia (Shaila et al., 1996) and Europe. The virus has been circulating in most African countries (Dhar et al., 2002). In Middle East and Arabian Peninsula; Iraq, Saudi Arabia, United Arab Emirates, Kuwait, Israel, Yemen and Oman are known to harbour infection. In Asia, the disease has been reported in India, Nepal, Bangladesh, Pakistan, Afghanistan and Iran, and in Europe. The disease now appears endemic throughout south Asia and beyond including Iran and Afghanistan. In Bangladesh, PPR has been endemic in goats since 1993. St. Martin's Island has no direct communication with the mainland. There is no history of vaccination against PPR in this island, but occasional outbreaks of PPR in goats are evident. The present study was carried out to detect PPRV-specific antibodies in the serum of cattle and goats using the monoclonal antibody-based c-ELISA.

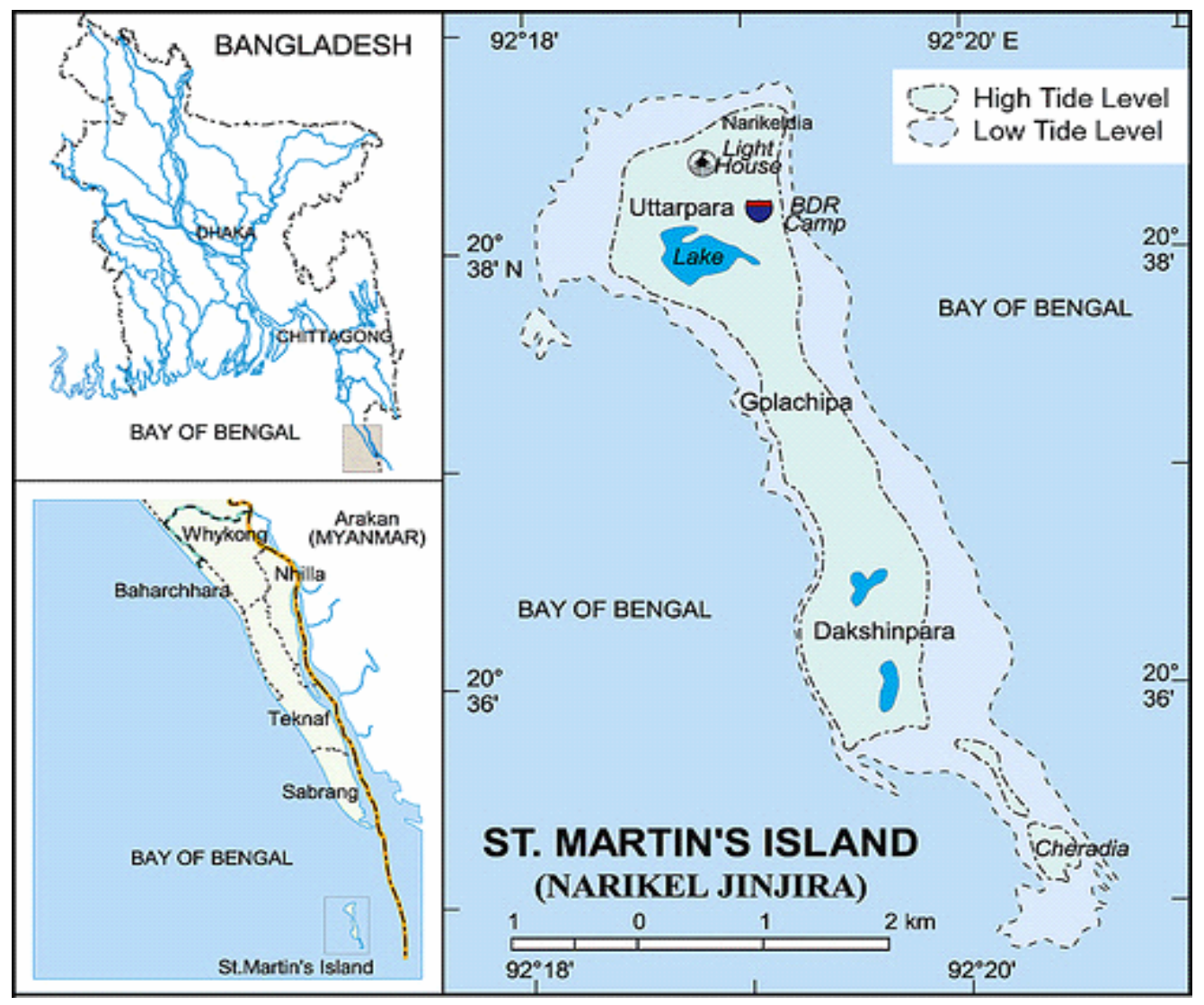

Fig. 1. Map of Saint Martin's Island in Bangladesh 


\section{Materials and Methods}

A total of 324 serum samples from 192 goats and 132 cattle (irrespective of age and sex) were collected from different locations of St. Martin's Island. Blood samples (10 $\mathrm{mL}$ ) were collected by jugular venipuncture without anticoagulant, kept for an hour at room temperature, and then serum was separated and stored at $-20^{\circ} \mathrm{C}$ until use. Competitive ELISA kit was used for the detection of antibodies against PPR virus by competitive screening ELISA (ID screen PPR competition- ID. Vet. Innovative Diagnostics). Briefly, $40 \mu \mathrm{L}$ of dilution buffer -13 (supplied kit) was added to each well. Positive control $(10 \mu \mathrm{L})$ was poured to wells A1 and B1 and negative control in $\mathrm{C} 1$ and D1 and $10 \mu \mathrm{L}$ samples were poured into the remaining wells. ELISA plate was then incubated at $37^{\circ} \mathrm{C}$ for 45 minutes. Each well was washed manually 3 times with approximately $300 \mu \mathrm{L}$ of wash solution, prepared by diluting the wash concentrate (20X) with double distilled water (supplied kit). About $100 \mu \mathrm{L}$ previously prepared single strength conjugate was added to each well and incubated at room temperature for 30 minutes. Further wash was done and $100 \mu \mathrm{L}$ substrate solutions were added to each well and incubated for 15 minutes in a dark room. Stop solution $(100 \mu \mathrm{L})$ was added to stop the reaction. Optical density (OD) values were recorded at $450 \mathrm{~nm}$ with ELISA plate reader (BIOTEK, INC.). The absorbance was converted to competition percentage $(\mathrm{CP})$ using following formula.

Competition percentage $(\mathrm{CP})=$ ODsample/ ODNC $\times 100$

Where, $\mathrm{NC}=$ negative control, $\mathrm{PC}=$ positive control

Test serum samples showing a CP value less than or equal to $35 \%$ were considered positive, greater than $35 \%$ and less than or equal to $45 \%$ were considered doubtful, and greater than $45 \%$ were considered negative.

The test was validated if the mean value of the negative control OD was greater than 0.7 and the mean value of the positive control (ODpc) was less than $30 \%$ of the ODNC.

\section{Results and Discussion}

Despite no history of PPR vaccination or Rinderpest outbreak, the overall seroprevalence was $37.5 \%$. In sheep and goats in Bangladesh an overall seroprevalence of PPR in goats of $21 \%$ has been reported, but varied greatly in different districts. Prevalence was highest in Jessore $(49.4 \%)$ south-west district and lowest $(6.3 \%)$ in Chittagong south-east district. Sero-prevalence was $26.7 \%$ in Rajshahi (North West), 20.0\% in Sylhet (North East), 12.5\% in Mymensingh (North East), and $10.5 \%$ in Dhaka (Central) (Bhuiyan et al., 2012). In mainland Bangladesh seroprevalence of PPR in cattle, buffalo and sheep was $3.7 \%, 42.4 \%$ and $16.0 \%$, respectively (unpublished data). Razzaque et al. (2004) found seroprevalence of $49.2 \%$ in goats, $36.0 \%$ in sheep and $19.1 \%$ in cattle. The presence of seropositive antibodies against PPRV in sheep, goats and cattle indicate that PPR viruses were circulating in these animals in Bangladesh. The seroprevalence was much higher in St. Martin's 
Island than in the closest area, Chittagong. The reason is not clear. The virus might be circulated to the Island from India, where Singh et al. (2004) reported the prevalence of antibodies to PPRV in goats of 2.1, 51.8, 40.1, 47.5, 62.7 and $41.5 \%$, respectively, at Meghalaya, Tamilnadu, Andhra Pradesh, Karnataka, Maharashtra and Gujarat of India. In another study, PPR antibody was in $41.7 \%$ of goats in a few northern states (Bhanuprakash et al., 2008) and $15.1 \%$ of goats in Kerala state in India (Janus et al., 2009). Balamurugan et al. (2014) reported seroprevalence of $21.8 \%$ against PPRV in five states (Andhra Pradesh, Gujarat, Jammu and Kashmir, Maharashtra and Rajasthan) of India. In the present study, no serum samples from cattle and $37.5 \%$ serum samples from goats were positive in PPR c-ELISA yielding a greater difference in seroprevalence of PPR. These differences may be due to easier transport of goats in comparison to cattle to the Island. In this study, the presence of PPRV antibodies indicated that PPR virus was circulating in the population, therefore, considering the geography of the Island, its lack of border security and the lack of PPR vaccination, it is suggested that as part of PPR control strategy the goat population should be vaccinated, and incoming goats should be kept in quarantine.

\section{References}

Abu-Elzein EME, Hassanien MM, Al-Afaleq AI, Abd-Elhadi MA, Housawi FMI 1990: Isolation of Peste des Petits Ruminants from goats in Saudi Arabia. Veterinary Record 127 309-310.

Balamurugan V, Krishnamoorthy P, Raju DSN 2014: Prevalence of Peste-des-petits-ruminant virus antibodies in cattle, buffaloes, sheep and goats in India. Virus Disease 25 85-90.

Bhanuprakash V, Saravanan P, Hosamani M, Balamurugan V, Mondal B, Singh RK 2008: Status of sheep sera to blue tongue, peste des petits ruminants and sheep pox in a few northern states in India. Veterinary Italiana 44 527-536.

Bhuiyan AR 2012: Epidemiology and Pathology of peste des petits Ruminants (PPR) in Bangladesh and Molecular Characterization of the virus. PhD Thesis, Department of Pathology, Faculty of Veterinary Science, Bangladesh Agricultural University, Mymensingh-2202.

Couacy-Hymann ERF, Bidjeh K, Angba A, DomenechJ, Diallo A 1995: Protection of goats against rinderpest by vaccination with attenuated peste des petits ruminants virus. Research in Veterinary Science 59 106-109.

Chowdhury EH, Bhuiyan AR, Rahman MM, Siddique MSA, Islam MR 2014: Natural PPR virus infection in Black Bengal goat: Virological, Pathological and ImmunoHistochemical investigations. BMC Veterinary Research 10263.

Dhar P, Sreenivasa BP, Barrett T, Singh RP, Bandyopadhyay SK 2002: Recent epidemiology of peste des petits ruminants virus (PPRV).Veterinary Microbiology 8 153-159.

Gibbs EP, Taylor WP, Lawman MI, Bryant I 1979: Classification of peste des petits ruminants virus as the fourth member of the genus Morbillivirus. Intervirology 11 268-274. 
Hamdy FM, Dardiri AH, Nduaka O, Breese SR, Ihemelandu EC 1976: Etiology of the stomatitis pneumoenteritis complex in Nigerian dwarf goats. Canadian Journal of Comparative Medicine 40 276-284.

Hussain M, Muneer R, Jahangir M, Awan AH, Khokhar MA, Zahur AB, Zulfiqar M, Hussain A 2003: Chromatographic strip technology: A pen side test for the diagnosis of peste des petits ruminants in sheep and goats. On-Line Journal of Biological Sciences 3 1-7.

Janus A, Tresamol PV, Saseendranath MP, Vijayakumar K, Pillai UN 2009: Seroprevalence of PPR of goats in Kerala by C ELISA . Journal of Veterinary and Animal Sciences 40 $15-16$.

Kitching RP 1988: The economic significance and control of small ruminant viruses in North Africa and West Asia. In: Textbook of increasing small ruminants productivity in semiarid areas (FS Thompson, ed), International Center for Agriculture Research in the Dry Areas (ICARDA). pp. 225-236.

Lefevre PC, Diallo A 1990: Peste des petits ruminants. Scientific and Technical Review; Revue Scientific et Technique (OIE) 9 951-965.

Murphy FA, Gibbs EPJ, Horzinek MC, Studdert MJ 1999: Classification and nomenclature of viruses. In: Textbook of Veterinary Virology, $3^{\text {rd }}$ Edn., Academic Press, New York. pp. 413.

Razzaque MA, Rahman MB, Kafi MA, Islam MR, Khan MFR, Nazir KHMNH 2004: Application of C-ELISA for detection of PPRV-specific antibodies in domestic ruminants in different areas of Mymensingh, Bangladesh. Molecular Biology and Biotechnology Journal 2 40-43.

Shaila MS, Shamaki D, Forsyth M, Diallo A, Goately L, Kitching RP, Barrett T 1996: Geographic distribution and epidemiology of peste des petits ruminants viruses. Virus Research 43 149-153.

Singh RP, Saravanan P, Sreenivasa BP, Singh RK, Bandyopadhyay SK 2004: Prevalence and distribution of peste des petits ruminants virus infection in small ruminants in India. Scientific and Technical Review; (OIE) 23 807-819.

Sudharshan KJ, Rajasekhar M, Upadhye AS 1995: Prevalence of peste des petits ruminants and rinderpest antibodies in small ruminants. Indian Veterinary Journal 72 1246-1250.

Taylor WP, Abegunde A 1979: The isolation of peste des petits ruminants virus from Nigerian sheep and goats. Research in Veterinary Science 26 94-96. 